\title{
Fast Food Addiction: A Major Public Health Issue
}

\author{
Abdul Kader Mohiuddin* \\ Nasirullah Memorial Trust, Bangladesh
}

*Corresponding author: Abdul Kader Mohiuddin, Nasirullah Memorial Trust, Tejgaon, Dhaka 1215, Bangladesh.

Received Date: December 30, 2019

Published Date: January 23, 2020

Abstract

Fast food/Junk food is designed to be tasty, comforting and convenient. Unfortunately, whilst these foods contain lots of calories, they often have far lower levels of fiber, water and minerals as compared to natural foods. Packaged food and snacks are also created specifically so that we get enough texture and taste from each bite to tantalize our taste buds; but not enough to make us feel full. It's evident that fast food feels good to eat and tempts us in many different situations. Fast food first popularized in the 1970s in the United States, which has today the largest fast food industry in the world. As taste, time considerations, convenience, and cost are major factors that contribute to an adolescent's or young adult's food choices, fast food restaurants serve as popular sites for their meals eaten outside the home. Current approaches suggest that fast food restaurants should be required to clarify nutrition information such as energy and fat content on their menu boards and on product packaging. This is important to help the consumer to make better food choices before purchasing. An adequate, nutritious, and balanced diet is essential to maintain health for one's lifetime. To achieve this healthy diet, fast food consumption should be limited.

Keywords: Morbidity and Overweight; Obesity Among Children; Junk Food; Stroke and Heart Diseases; Food Induced Neurodegeneration; Carbonated Beverages; Red Meat Over-Consumption; Food Effects in Fertility and Sex Drive; Artificial Sweeteners and Condensed Milk

\section{Introduction}

Menus, as lists of prepared foods, provides origin of the food items (Thai, Chinese, Continental), restaurant's mission, chef's philosophy of cooking, brief idea about food processing, special combo offers along with their cost. The colorful menu or flyers attracts fast food lovers to spend more and more in their favorite restaurants for both its decadent yumminess and its ultra-convenience. High income, rapid urbanization, free home deliveries, mouthwatering advertisements and international cuisines have contributed to a rising trend in increased junk food intake. Calculation of monetary cost gets more priorities than the actual hidden health costs, as usual. The growing widespread use of fast food among adolescents and young adults is of concern due to the high fat and energy intake, which may cause obesity and subsequently obesity-related chronic diseases. The added fat, sugar, and salt create a taste that makes people crave these foods, a sensation that many describe as an addiction. Increase in the junk food consumption is a global phenomenon having a prevalence of around 70\% [1]. US fast-food sales increased exponentially between 1970 and 2000, from $\$ 6$ billion to $\$ 110$ billion [2]. During this time, obesity rates among US adults doubled and it is expected that $85 \%$ of US citizens will be affected by obesity by 2030 [3]. The real-life cost of fast foods in terms of obesity, diabetes and cardiac complications are well documented, repeated several times in newspapers, health bulletins, journals and so on. New York city became the first jurisdiction in the US to require restaurant chains to post calorie information on menus and menu boards [4]. However, the dark side of the fast food consumption is not ended yet, some more are there to look forward (Figure 1). 


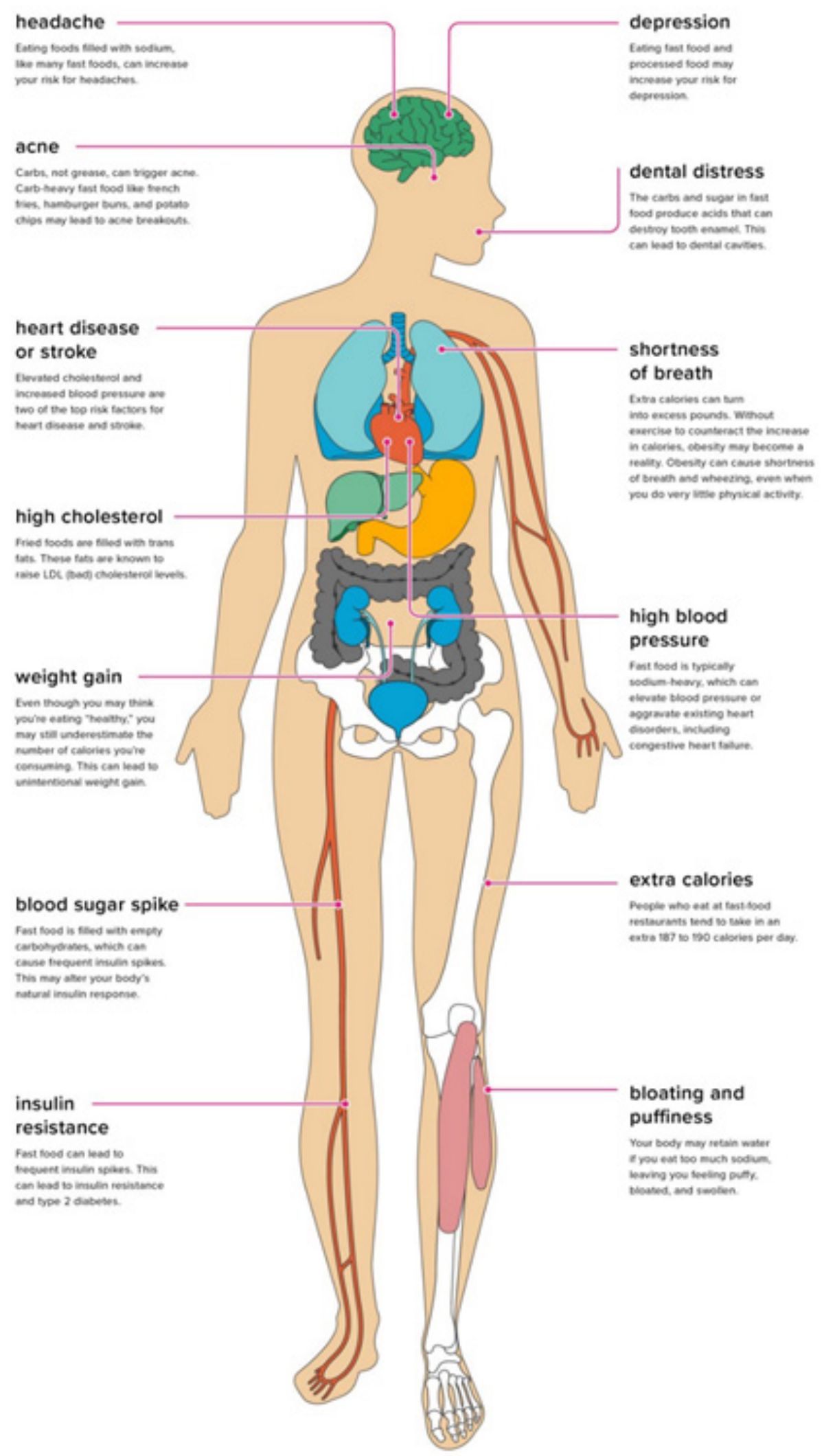

Figure 1: The Effects of Fast Food on the Body (Source: Healthline).

\section{Obesity}

Most of the fast food contains a large amount of sugar, fats and carbs and less minerals and vitamins. This means that people are taking in large amounts of unhealthy calories in the shape of fast food which leads to weight gain and ultimately obesity. In a Brazilian study, several products were identified as obesogenic: sweets and sugar, typical rich food dishes, pastries, fast food, oils, milk, cereals, cakes and sauces [5]. Obesity is linked to several long-term health conditions, premature death and illness including 
diabetes, heart disease, stroke, gall bladder disease, fatty liver, arthritis and joint disorders and some cancers [6]. In a newspaper interview, Professor AK Azad Khan, President, Diabetic Association of Bangladesh said $40 \%$ school going children of Dhaka city were either obese or overweight [7]. A community level cross-sectional study in Bangladesh, Hossain et.al, 2019 reported that nearly $65 \%$ of the mothers of preschool aged children were not aware of childhood obesity as a health problem [8]. Fast food consumption habit has been found as a potential risk factor for overweight and/ or obesity among children in other studies $[9,10]$. Also, Al Muktadir et.al, 2019 reported that (systematic random sampling attending in 27 established public and private universities) more than $40 \%$ of the youth went to fast food restaurants at least once per week and over $27 \%$ went regularly ( 2 times/week). Youth having fast foods 2 times/week, consuming soft drinks 3-4 times/week were more likely to be obese [11]. Processed and fast foods contain high amounts of saturated fats. Fast foods reduce the quality of diet and provide unhealthy choices especially among children and adolescents raising their risk of obesity (Figure 2).

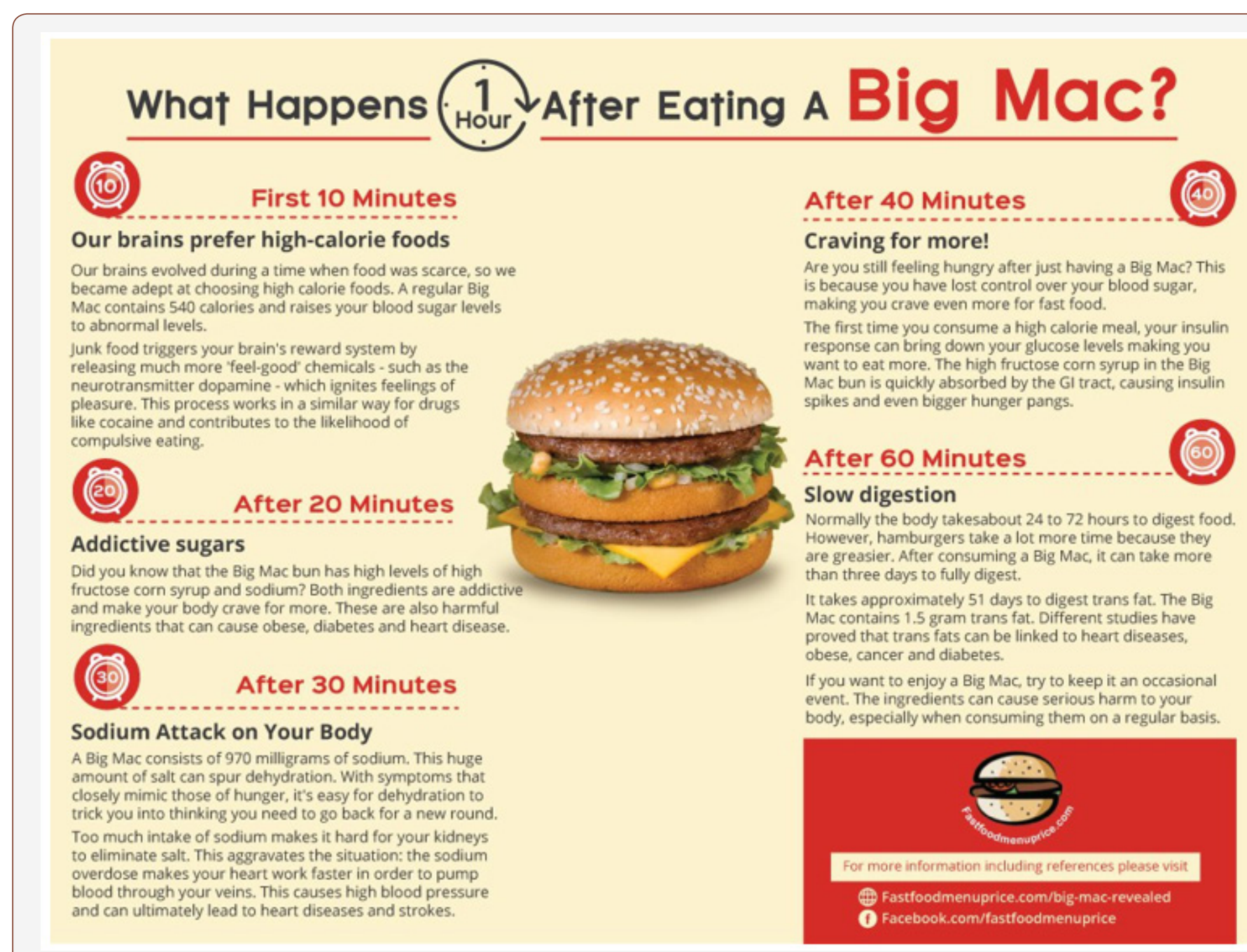

Figure 2: One Hour After Eating A Big Mac. The website 'Fast Food Menu Price' created this infographic outlining what happens to body inside after an hour following ingestion of a Big Mac. It also might shed some light on why we all like fast food so much, even though we're aware it's bad for our health (Source: awesomeinventions.com).

\section{Diabetes}

Junk food includes many types of fast food, processed foods, and premade snack foods. Fast food is often highly processed, and this can have a negative impact on health. Fast food consumption and outof-home eating behavior is a main risk factor for lower diet quality, higher calorie and fat intake and lower micronutrients density of diet [12]. The fast food market is mostly unregulated in Bangladesh with no government policy to control pricing and advertisements giving the way of new global chains in the market. Consumption of fast foods $\geq 2$ times/week increased the risk of insulin resistance and T2DM. Frequent consumption of fast foods was accompanied with overweight and abdominal fat gain, impaired insulin and glucose homeostasis, lipid and lipoprotein disorders, induction of systemic inflammation and oxidative stress [13]. Fast food restaurants were found to be positively associated with diabetes prevalence in all counties except high poverty/medium-minority [14]. Research has shown that excess calories shorten lifespan, whereas moderate caloric restriction slows the aging process and protects the body and brain [15]. Overweight and obesity are major risk factors for type 2 diabetes. Again, nitrosamines of processed 
meats, mostly used in fast foods, have been demonstrated to be toxic to beta cells and subsequently to increase the risk of T2D in animal studies [16]. Higher pre-pregnancy consumption of fast foods was associated with an increased risk of diabetes in pregnancy and high birthweight in first-time mothers, found in a southwest Sydneybased study [17].

\section{Stroke}

Stroke, previously thought a condition belonging to the elderly, is now increasingly a middle-aged health problem too. Healthy lifestyle choices reduce the risk of stroke by $\sim 80 \%$, according to Spence, 2019. Also, each $5 \mathrm{~kg} / \mathrm{m}^{2}$ increase in BMI, within the range of $25-50 \mathrm{~kg} / \mathrm{m} 2$ is associated with about $40 \%$ higher stroke mortality [18]. Higher consumption of fast food was associated with higher BMI Z score [13]. Frequent consumption of fast food, $\geq 2$ times/week, compared to $<1$ time/week, has been accompanied with $\geq 4.5 \mathrm{~kg}$ weight gain during a fifteen-year follow-up of US adolescents and young adults, says the same study. Fuhrman, 2018 stated that eating unhealthier fast and processed foods 7 -fold increase the risk of early-life stroke [15]. Vaitkevičiūtė et.al, 2019 also pointed associations between the frequencies of consumption of unhealthy, high-fat food, soft drinks and higher BMI in children [19]. Wall et.al, 2018 found an inverse association between BMI and higher consumption of fruit, vegetables, pulses and nuts in adolescents [20]. There was a significant association between fast food restaurants and stroke risk in neighborhoods in a communitybased study. Accessibility to fast food restaurants may be one pathway by which neighborhood disadvantage contributes to atherosclerosis [21]. Interestingly, living farther away from a fast food restaurant was found to be associated with lower BMI for children, as reported by Huang et.al, 2019 [22]. Caffeinated energy drinks have also been associated with seizures and stroke [23].

\section{Heart Diseases}

The prevalence of fast food consumption, obesity and hypertension is high among children in major cities in China, according to Zhao et.al, 2017. 16-20\% of Chinese children have high BP [24]. Association between increased BMI and hypertension in children with fast food is also detailed in another study done in Sikkim, India [25]. A significant association was found between fast food consumption, BP levels, and anthropometric indices in another Iranian study among children [26]. Body size has a major impact on the association between intake of the modern dietary pattern and hypertension. Alsabieh et.al, 2019 demonstrates that increased systolic BP significantly correlated with an increase in BMI [27]. Both Kar et.al and Bahadoran et.al, 2015 supports association between increased BMI and fast food [13], [25]. Shi et.al, 2019 concluded that reducing the consumption of modern fast foods is important to prevent hypertension in Thailand [28]. Higher consumption of fast foods and higher exposure to multiple sources of accessible, cheap, energy-dense fast foods were also accompanied with a 56-162\% increased risk of coronary heart disease mortality [13].

\section{Neurodegeneration and Psychological Changes}

Several cross-sectional studies have found significant associations between poor nutritional status and behavioral disturbances, worse cognitive status, and more impaired functioning in adult daily living activities [27]. Fat-filled snack foods may heighten the risk of developing advanced age-related neuro-degeneration, the leading cause of vision and hearing impairment [29]. Researchers from the University of Bristol warn that such poor diets can also permanently damage the nervous system, particularly vision [4]. It negatively affects brain health by damaging regions relevant to memory tasks and by diminishing brain-derived neurotrophic factor levels. This amplifies the risk of developing dementia and Alzheimer's disease later in life [6], [27]. Also, presence of depressive symptoms is positively associated with fast-food intake [30] and junk food consumption may increase the risk for psychiatric distress and violent behaviors in children and adolescents [31,32]. A study among Iranian children and adolescents reveals that junk food consumption was significantly associated with mental distress, including "worry, depression, confusion, insomnia, anxiety, aggression, and feelings of being worthless" [33]. In addition, caffeine content of cola and carbonated beverages are responsible for hyperactivity/attention deficit in children [34].

\section{Headache/Precipitation of Migraine}

Monosodium Glutamate is one of the most widely used foodadditives in commercial foods. It has linked with obesity, metabolic disorders, thyroid disorders, Chinese Restaurant Syndrome (headache, skin flushing, and sweating), neurotoxic effects and detrimental effects on the reproductive organs [35-39]. As it triggers tenderness of the peri-cranial muscles (most prominent clinical finding in tension-type headache), people with migraine should strictly avoid it. The absence of a significant relationship between processed meat products and canned foods consumption and migraine headache might be due to people's interest in traditional foods and lack of tendency to consume fast foods in Iran [40]. The interruption of daily consumption of caffeine-containing beverages can cause headache and other symptoms within 8 hours [41]. Also, caffeine abstinence is associated with better efficacy of acute migraine treatment [42].

\section{Physical Performance}

A Newcastle-based study among elderly people shows that dietary pattern high in red meats, potato or butter may adversely affect muscle strength and physical performance in later life [43]. The fat and sugar levels in junk foods stress the metabolism, causing it to work less effectively. Particularly daily consumption of junk food may be associated with poorer mental and physical health [44]. Abstaining from junk foods is one way to keep cholesterol levels low and prevent clogged arteries, which can reverse the symptoms of heart disease and improve athletic performance. Excess consumption of junk food can affect the physical as well as mental performance of children. Addiction of junk-food in early 
age may cause serious illness in later age. The harmful effect of junk-food are overweight, low physical stamina and other health problems among adolescents [45,46]. Also, Stokes et.al, 2018 suggested fast food alternatives to young athletes [47] (Figure 3).

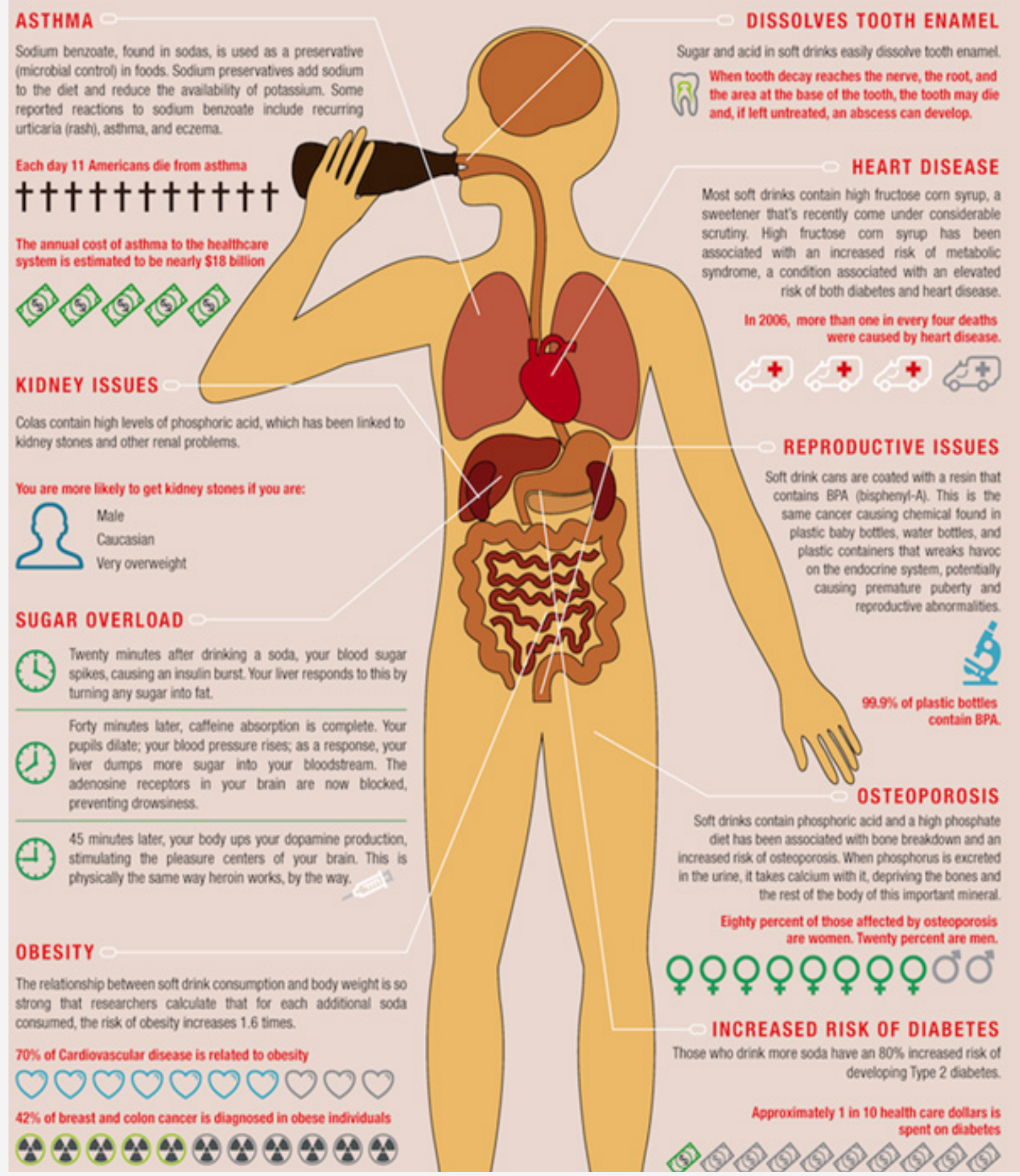

Figure 3: Health Impact of Carbonated Beverages (Source: Daily Infographic).

\section{Cancers and Auto-Immune Disorders}

Gluten, another notorious protein responsible for auto-immune disorders, was found in more than 50\% pizza and pasta samples in "Gluten-Free" labelled restaurants [47]. A new study in PLOS Medicine finds eating unhealthy food is associated with a higher risk of developing cancer [48]. People who ate the most junk food showed a higher risk of stomach, colorectal, and surprisingly, lung cancers. Separately, men showed a higher risk of lung cancer, and women showed a higher risk of liver and postmenopausal breast cancers [49]. Nitrate and nitrite, which are abundant in processed meats, are potential carcinogens found in breast, prostate, pancreas, colorectal cancers along with non-alcoholic fatty liver disease and insulin resistance [50-58]. Beyond nutritional composition, neoformed contaminants, some of which have carcinogenic properties (such as acrylamide, heterocyclic amines, and polycyclic aromatic hydrocarbons), are present in heat treated processed food products as a result of the Maillard reaction, says Cangemi et.al, 2019 [59]. Again, Buckley et.al, 2019 demonstrated that the packaging of ultra- 
processed foods may contain some materials in contact with food for which carcinogenic and endocrine disruptor properties have been postulated, such as bisphenol A [60]. Finally, ultra-processed foods contain authorized, but controversial, food additives such as sodium nitrite in processed meat or titanium dioxide (TiO2, white food pigment), for which carcinogenicity has been suggested in animal or cellular models [59], [61]. Interestingly, people hooked on fast food and have limited intake of vegetables and fruits. High salt intake, including salt preserved foods, smoked or dried meat and fish, pickled food, low intake of fresh fruit and vegetables, obesity are among the most contributory to stomach and colorectal cancers [62].

\section{Gut, Bone Health \& Premature Aging}

A moderate increased risk of irritable bowel syndrome is reported in a French Internet based study [63]. Symptoms of bloating, gas, or pain passing bowel movements may be aggravated by high fast food consumption [64]. Use of Aspartame, a low-calorie sugar substitute in Coke Zero or Diet Coke is still controversial due to possibility of cancer development [65]. Another study says that a high-fat diet alters the structure of the microbiome even in the absence of obesity [66]. Western diet is characterized by a high intake of saturated and omega- 6 fatty acids, reduced omega- 3 fat intake, an overuse of salt, and too much refined sugar [67]. "Ingestion of sugar, in particular, can accelerate premature aging", says The Journal of Clinical and Aesthetic Dermatology [68], as exceeded free blood sugar promotes cross-linking of skin collagen fibers [69]. Fast food and carbonated beverages often contain large amounts of phosphate additives. This, according to another leading journal In Vivo, hampers kidney function and bone health [70].

\section{Reproductive Health}

Over-consumption of cheese, yogurt, modified grains (bread, pasta, crackers, cereals) may jeopardize testosterone, male sex hormone that plays a major role in fertility and sex drive, according to Dr. Michael Hirt, founder of the Center for Integrative Medicine in California [71]. In addition, diets that are low in whole-grain foods, legumes, vegetables and fruits, and high in red meat, full-fat dairy products, and sugary foods and beverages are all associated with an increased risk of erectile dysfunction [72]. An official publication of the Federation of Obstetrics and Gynecological Societies of India says that popularity of junk food in adolescence are responsible for the increasing polycystic ovarian syndrome in adolescent girls and is challenge for gynecologists treating them [73]. Market available ice creams or raita salads in hotel-restaurants are storehouse of $\mathrm{E}$. coli bacteria, can be responsible for diarrhea, abdominal cramp, fever, vomiting and uncomplicated urinary infections sometimes [74]. The so-called condensed milk added as artificial sweeteners is nothing but over-boiled palm oil that deposits in the deep tissues, imparts metabolic disorders and poorly eliminates.

\section{Conclusion and Recommendations}

Children and adolescents are exposed to various forms of food marketing while using social media applications, most of which promotes unhealthy foods [75]. Teenagers are aggressively targeted by food marketing messages (primarily for unhealthy foods) and susceptible to this messaging due to developmental vulnerabilities and peer-group influence [76]. Fast-food consumption is associated with lower diet quality [77]. Healthier foods cost nearly twice as much as unhealthier foods per serving on an average among high income countries [78]. Americans allocate more than $40 \%$ of their food budget to restaurants and fast foods [40]. The scenario is opposite in Bangladesh. In capital city, people often pay restaurant bills equivalent to more than $500 \%$ cost involved in regular meals. Again, traditional fast foods including Singara, Samucha, Puri, Piaju, Lachcha Shemai and Paratha all are generally deeply fried. Commercially available packaged bakery and fast foods often do not contain any declaration of their fat content [79]. Occasional fast food consumption (considered as cheat foods) has been encouraged in various bodybuilding websites, as it stimulates many enzymes that were previously deactivated. But in Bangladesh, NonCommunicable Disease Risk Factor Survey 2013, consumption of inadequate fruit and/or vegetables ( $<5$ servings per day) was found in more than $90 \%$ people [80]. Strong advocacy on the detrimental effects of fast food consumption should be routinely done in educational institutions. But Alas! Most fast foods are consumed by youth and children from the nearby shops of educational institutions or the canteens run by the institutions themselves.

\section{Acknowledgement}

I'm thankful to Dr. Colin D. Rehm, Clinical Assistant Professor, Department of Epidemiology \& Population Health, Alert Einstein College of Medicine, NY, USA for her precious time to review my literature and thoughtful suggestions. Also, I'm also grateful to seminar library of Faculty of Pharmacy, University of Dhaka and BANSDOC Library, Bangladesh for providing me books, journal and newsletters.

\section{Conflict of Interest}

The author declares that he has no competing interests.

\section{References}

1. Mandoura N, Al-Raddadi R, Abdulrashid O, Shah HBU, Kassar SM, et al. (2017) Factors Associated with Consuming Junk Food among Saudi Adults in Jeddah City. Cureus 9(12): e2008.

2. Dumanovsky T, Huang CY, Bassett MT, Silver LD (2010) Consumer awareness of fast-food calorie information in New York City after implementation of a menu labeling regulation. Am J Public Health 100(12): 2520-2525.

3. Al-Ghamdi S, Shubair MM, Aldiab A, Al-Zahrani JM, Aldossari KK, et al. (2018) Prevalence of overweight and obesity based on the body mass index; a cross-sectional study in Alkharj, Saudi Arabia. Lipids Health Dis 17(1): 134 .

4. Gruner J, DeWeese RS, Lorts C, Yedidia MJ, Ohri-Vachaspati P (2018) Predicted Impact of the Food and Drug Administration's Menu-Labeling Regulations on Restaurants in 4 New Jersey Cities. Am J Public Health 108(2): 234-240.

5. Santos NH, Fiaccone RL, Barreto ML, Silva LA, Silva Rde C (2014) Association between eating patterns and body mass index in a sample of children and adolescents in Northeastern Brazil. Cad Saude Publica 30(10): 2235-2245. 
6. Hruby A, Hu FB (2015) The Epidemiology of Obesity: A Big Picture. Pharmacoeconomics 33(7): 673-689.

7. Mohiuddin AK (2019) TRACK Implementation among Bangladeshi Population. Int J Diabetol Vasc Dis Res 7(4): 254-260.

8. Hossain MS, Siddiqee MH, Ferdous S, Faruki M, Jahan R, et al. (2019) Is Childhood Overweight/Obesity Perceived as a Health Problem by Mothers of Preschool Aged Children in Bangladesh? A Community Level Cross-Sectional Study. Int J Environ Res Public Health 16(2): 202.

9. Bhuiyan MU, Zaman S, Ahmed T (2013) Risk factors associated with overweight and obesity among urban school children and adolescents in Bangladesh: a case-control study. BMC Pediatr 13: 72.

10. Alam MM, Hawlader MDH, Wahab A, Hossain MD, Nishat SA, et al. (2019) Determinants of overweight and obesity among urban schoolgoing children and adolescents: a case-control study in Bangladesh. Int J Adolesc Med Health.

11. Al Muktadir MH, Islam MA, Amin MN, Ghosh S, Siddiqui SA, et al (2019) Nutrition transition - Pattern IV: Leads Bangladeshi youth to the increasing prevalence of overweight and obesity. Diabetes Metab Syndr.

12. Lee KW, Song WO, Cho MS (2016) Dietary quality differs by consumption of meals prepared at home vs. outside in Korean adults. Nutr Res Pract 10(3): 294-304.

13. Bahadoran Z, Mirmiran P, Azizi F (2016) Fast Food Pattern and Cardiometabolic Disorders: A Review of Current Studies. Health Promot Perspect 5(4): 231-240.

14. Haynes-Maslow L, Leone LA (2017) Examining the relationship between the food environment and adult diabetes prevalence by county economic and racial composition: an ecological study. BMC Public Health 17(1): 648.

15. Fuhrman J (2018) The Hidden Dangers of Fast and Processed Food. Am J Lifestyle Med 12(5): 375-381.

16. Beigrezaei S, Ghiasvand R, Feizi A, Iraj B (2019) Relationship between Dietary Patterns and Incidence of Type 2 Diabetes. Int J Prev Med 10: 122 .

17. Wen LM, Simpson JM, Rissel C, Baur LA (2013) Maternal "junk food" diet during pregnancy as a predictor of high birthweight: findings from the healthy beginnings trial. Birth 40(1): 46-51.

18. Spence JD (2019) Nutrition and Risk of Stroke. Nutrients. 11(3): 647.

19. Vaitkeviciute J, Petrauskiene A (2019) The Associations between Body Mass Index of Seven- and Eight-Year-Old Children, Dietary Behaviour and Nutrition-Related Parenting Practices. Medicina (Kaunas) 55(1): 24.

21. Morgenstern LB, Escobar JD, Sánchez BN, Hughes R, Zuniga BG, et al. (2009) Fast food and neighborhood stroke risk. Ann Neurol 66(2): 165170.

22. Huang Y, Huang D, Nguyen QC (2019) Census Tract Food Tweets and Chronic Disease Outcomes in the U.S., 2015-2018. Int J Environ Res Public Health 16(6): 975.

23. Lipton RB, Diener HC, Robbins MS, Garas SY, Patel K (2017) Caffeine in the management of patients with headache. J Headache Pain. 18(1): 107.

24. Zhao Y, Wang L, Xue H, Wang H, Wang Y (2017) Fast food consumption and its associations with obesity and hypertension among children: results from the baseline data of the Childhood Obesity Study in China Mega-cities. BMC Public Health 17(1): 933

25. Kar S, Khandelwal B (2015) Fast foods and physical inactivity are risk factors for obesity and hypertension among adolescent school children in east district of Sikkim, India. J Nat Sci Biol Med 6(2): 356-359.

26. Payab M, Kelishadi R, Qorbani M, Motlagh ME, Ranjbar SH, et al. (2015) Association of junk food consumption with high blood pressure and obesity in Iranian children and adolescents: the CASPIAN-IV Study. J Pediatr (Rio J) 91(2): 196-205.

27. Alsabieh M, Alqahtani M, Altamimi A, Albasha A, Alsulaiman A, et al. (2019) Fast food consumption and its associations with heart rate, blood pressure, cognitive function and quality of life. Pilot study. Heliyon 5(5): e01566.
28. Shi Z, Papier K, Yiengprugsawan V, Kelly M, Seubsman SA, et al. (2019) Dietary patterns associated with hypertension risk among adults in Thailand: 8-year findings from the Thai Cohort Study. Public Health Nutr 22(2): 307-313.

29. Morris S (2019) Teenager loses sight as eating disorder leads to malnutrition. The Guardian.

30. Khosravi M, Sotoudeh G, Majdzadeh R, Nejati S, Darabi S (2015) Healthy and Unhealthy Dietary Patterns Are Related to Depression: A CaseControl Study. Psychiatry Investig 12(4): 434-442.

31. Zahedi H, Kelishadi R, Heshmat R, Motlagh ME, Ranjbar S, et al. (2014) Association between junk food consumption and mental health in a national sample of Iranian children and adolescents: the CASPIAN-IV study. Nutrition 30(11-12): 1391-1397.

32. Hemmingsson E (2018) Early Childhood Obesity Risk Factors: Socioeconomic Adversity, Family Dysfunction, Offspring Distress, and Junk Food Self-Medication. Curr Obes Rep 7(2): 204-209.

33. Mozafarian N, Motlagh ME, Heshmat R (2017) Factors Associated with Screen Time in Iranian Children and Adolescents: The CASPIAN-IV Study. Int J Prev 8: 31

34. Anjum I, Jaffery SS, Fayyaz M, Wajid A, Ans AH (2018) Sugar Beverages and Dietary Sodas Impact on Brain Health: A Mini Literature Review. Cureus 10(6): e2756.

35. Niaz K, Zaplatic E, Spoor J (2018) Extensive use of monosodium glutamate: A threat to public health?. EXCLI J 17: 273-278.

36. Hernández Bautista RJ, Mahmoud AM, Königsberg M, López Díaz Guerrero NE. (2019) Obesity: Pathophysiology, monosodium glutamateinduced model and anti-obesity medicinal plants. Biomed Pharmacother 111: 503-516.

37. Bawaskar HS, Bawaskar PH, Bawaskar PH (2017) Chinese Restaurant Syndrome. Indian J Crit Care Med 21(1): 49-50.

38. Zehra Kazmi, Iffat Fatima, Shaghufta Perveen, Saima Shakil Malik (2017) Monosodium glutamate: Review on clinical reports, International Journal of Food Properties 20(sup2): 1807-1815

39. Jubaidi FF, Mathialagan RD, Noor MM, Taib IS, Budin SB (2019) Monosodium glutamate daily oral supplementation: study of its effects on male reproductive system on rat model. Syst Biol Reprod Med 65(3): 194-204.

40. Nazari F, Eghbali M (2012) Migraine and its relationship with dietary habits in women. Iran J Nurs Midwifery S65-S71.

41. Weber JG, Ereth MH, Danielson DR (1993) Perioperative ingestion of caffeine and postoperative headache. Mayo Clin Proc 68(9): 842-5.

42. Lee MJ, Choi HA, Choi H, Chung CS (2016) Caffeine discontinuation improves acute migraine treatment: a prospective clinic-based study. J Headache Pain 17(1): 71.

43. Granic A, Jagger C, Davies K (2016) Effect of Dietary Patterns on Muscle Strength and Physical Performance in the Very Old: Findings from the Newcastle 85+ Study. PLoS One 11(3): e0149699.

44. Zahra J, Ford T, Jodrell D (2014) Cross-sectional survey of daily junk food consumption, irregular eating, mental and physical health and parenting style of British secondary school children. Child Care Health Dev 40(4): 481-91.

45. Kashyap R, Joglekar A, Verma S (2014) Effect of Junk Food on Physical Performance of School Children. Ind J Sci Res and Tech 2(4): 21-25.

46. Lamba A, Garg V (2017) Impact of junk food on health status and physical performance of school going children (12-16 Years). International Journal of Food Science and Nutrition 2(6): 49-51.

47. Stokes EG, Hughes R, Shaw DM, O'Connor HT, Beck KL (2018) Perceptions and Determinants of Eating for Health and Performance in High-Level Male Adolescent Rugby Union Players. Sports (Basel) 6(2): 49.

48. Lerner BA, Phan Vo LT, Yates S, Rundle AG, Green PHR, et al. (2019) Detection of Gluten in Gluten-Free Labeled Restaurant Food: Analysis of Crowd-Sourced Data. Am J Gastroenterol 114(5): 792-797. 
49. Deschasaux M, Huybrechts I, Murphy N, Julia C, Hercberg S, et al. (2018) Nutritional quality of food as represented by the FSAm-NPS nutrient profiling system underlying the Nutri-Score label and cancer risk in Europe: Results from the EPIC prospective cohort study. PLoS Med 15(9): e1002651.

50. Scutti S (2018) Eating junk food tied to higher risk of numerous cancers. CNN Health.

51. Xie L, Mo M, Jia HX, Liang F, Yuan J, et al. (2016) Association between dietary nitrate and nitrite intake and sitespecific cancer risk: evidence from observational studies. Oncotarget 7(35): 56915-56932.

52. Inoue-Choi M, Sinha R, Gierach GL, Ward MH (2016) Red and processed meat, nitrite, and heme iron intakes and postmenopausal breast cancer risk in the NIH-AARP Diet and Health Study. Int J Cancer 138(7): 16091618.

53. Sinha R, Park Y, Graubard BI, Leitzmann MF, Hollenbeck A et al. (2009) Meat and meat-related compounds and risk of prostate cancer in a large prospective cohort study in the United States. Am J Epidemiol 170(9): 1165-1177.

54. Aykan NF (2015) Red Meat and Colorectal Cancer. Oncol Rev 9(1): 288.

55. Quist AJL, Inoue-Choi M, Weyer PJ Anderson K, Cantor KP et al. (2018) Ingested nitrate and nitrite, disinfection by-products, and pancreatic cancer risk in postmenopausal women. Int J Cancer 142(2): 251-261.

56. Perdomo CM, Frühbeck G, Escalada J (2019) Impact of Nutritional Changes on Nonalcoholic Fatty Liver Disease. Nutrients 11(3): 677

57. Ma L, Hu L, Feng X, Wang S (2018) Nitrate and Nitrite in Health and Disease. Aging Dis 9(5): 938-945.

58. Bouvard V, Loomis D, Guyton KZ, Grosse Y, Ghissassi FE et al. (2015) International Agency for Research on Cancer Monograph Working Group. Carcinogenicity of consumption of red and processed meat. Lancet Oncol 16(16): 1599-600.

59. Cangemi DJ, Lacy BE (2019) Management of irritable bowel syndrome with diarrhea: a review of nonpharmacological and pharmacological interventions. Therap Adv Gastroenterol 12: 1756284819878950.

60. Buckley JP, Kim H, Wong E, Rebholz CM (2019) Ultra-processed food consumption and exposure to phthalates and bisphenols in the US National Health and Nutrition Examination Survey, 2013-2014. Environ Int 131: 105057.

61. Marion-Letellier R, Amamou A, Savoye G, Ghosh S (2019) Inflammatory Bowel Diseases and Food Additives: To Add Fuel on the Flames!. Nutrients 11(5): 1111.

62. American Institute for cancer Research. Diet, nutrition, physical activity and stomach cancer (Revised 2018).

63. Buscail C, Sabate JM, Bouchoucha M (2017) Western Dietary Pattern Is Associated with Irritable Bowel Syndrome in the French NutriNet Cohort. Nutrients 9(9):986.

64. Okawa Y, Fukudo S, Sanada H (2019) Specific foods can reduce symptoms of irritable bowel syndrome and functional constipation: a review. Biopsychosoc Med 13: 10.
65. Can Aspartame Cause Cancer? The Facts. Healthline, March 21, 2019.

66. Myles IA (2014) Fast food fever: reviewing the impacts of the Western diet on immunity. Nutr J 13: 61.

67. Potvin Kent M, Pauzé E, Roy EA, De Billy N, Czoli C (2019) Children and adolescents' exposure to food and beverage marketing in social media apps. Pediatr Obes 14(6): e12508.

68. Katta R, Desai SP (2014) Diet and dermatology: the role of dietary intervention in skin disease. J Clin Aesthet Dermatol 7(7): 46-51.

69. Clatici VG, Racoceanu D, Dalle C, Voicu C, Tomas-Aragones L et al. (2017) Perceived Age and Life Style. The Specific Contributions of Seven Factors Involved in Health and Beauty. Maedica (Buchar) 12(3): 191-201.

70. Shimada M, Shutto-Uchita Y, Yamabe H (2019) Lack of Awareness of Dietary Sources of Phosphorus Is a Clinical Concern. In Vivo 33(1): 1116.

71. Gordon L (2018) Foods that are killing your sex drive. FOXNEWS.

72. Yafi FA, Jenkins L, Albersen M (2016) Erectile dysfunction. Nat Rev Dis Primers 2: 16003.

73. Rathod AD, Chavan RP, Pajai SP, Bhagat V, Thool P (2016) Gynecological Problems of Adolescent Girls Attending Outpatient Department at Tertiary Care Center with Evaluation of Cases of Puberty Menorrhagia Requiring Hospitalization. J Obstet Gynaecol India 66(1): 400-406.

74. Hebbelstrup Jensen B, Olsen KE, Struve C, Krogfelt KA, Petersen AM (2014) Epidemiology and clinical manifestations of enteroaggregative Escherichia coli. Clin Microbiol Rev 27(3): 614-630.

75. Potvin Kent M, Pauzé E, Roy EA, de Billy N, Czoli C (2019) Children and adolescents' exposure to food and beverage marketing in social media apps. Pediatr Obes 14(6): e12508.

76. Truman E, Elliott C (2019) Identifying food marketing to teenagers: a scoping review. Int J Behav Nutr Phys Act 16(1): 67.

77. Barnes TL, French SA, Mitchell NR, Wolfson J (2016) Fast-food consumption, diet quality and body weight: cross-sectional and prospective associations in a community sample of working adults. Public Health Nutr 19(5): 885-892.

78. Kern DM, Auchincloss AH, Stehr MF, Roux, Moore, et al. (2017) Neighborhood Prices of Healthier and Unhealthier Foods and Associations with Diet Quality: Evidence from the Multi-Ethnic Study of Atherosclerosis. Int J Environ Res Public Health 14(11): 1394.

79. Islam AK, Majumder AA (2013) Coronary artery disease in Bangladesh: a review. Indian Heart J 65(4): 424-435.

80. Zaman MM, Bhuiyan MR, Karim MN, Moniruz Zaman, Rahman, et al. (2015) Clustering of non-communicable diseases risk factors in Bangladeshi adults: An analysis of STEPS survey 2013. BMC Public Health 15: 659. 